\title{
DIE SCHLACHTEN UM METZ
}

„Man hatte mir erzählt, daß besonders tüchtige Soldaten, wenn sie sich in den Kampf stürzten, dabei wie berauscht sind und sogar Lustgefühle empfinden. Wenn ich für meinen Teil versuchte, mir solche Lustgefühle vorzustellen, wurde mir für mindestens acht Tage übel.“

Louis-Ferdinand Céline ${ }^{1}$

\section{Mars-la-Tour, Gravelotte und die Folgen}

In sengender Augusthitze erreichten die erste und die zweite deutsche Armee am 14. August das Gebiet westlich und südwestlich von Metz. Dort kam es bei Colombey-Nouilly ${ }^{2} \mathrm{zu}$ einem ersten von deutscher Seite keineswegs geplanten Aufeinandertreffen ${ }^{3}$ mit Verbänden der Rheinarmee, das unentschieden endete. Das Gebiet um die Festung wurde zum Hauptkriegsschauplatz. Panikartig waren die meisten Umwohner der Stadt vor den heranrückenden Preußen mit ihrem Hab und Gut in die Festung geflohen, wobei zuletzt nur noch jene Aufnahme fanden, die für vierzig Tage Verpflegung mitführten ${ }^{4}$. Auch unter den französischen Soldaten hatten sich erste Auflösungserscheinungen gezeigt. Aufschlußreich ist ein Tagesbefehl General Decaens, Kommandant des III. Corps: „Soldaten“, so hieß es da, „die ihr Gewehr verloren haben, werden ohne Waffen auf Vorposten geschickt und bleiben ohne Ausrüstung, bis sie einem feindlichen Soldaten dieselbe abgenommen haben."

Das Terrain, auf dem die beiden großen Schlachten vom 16. und 18. August stattfinden werden, ist das sanft gewellte, fruchtbare Hügelland Westlothringens zwischen Mosel und Maas. Waldreich und zerklüftet fällt der Ostrand steil ins Moseltal ab. Zentral liegt das Örtchen Gravelotte mit seinen für die Gegend typisch massiv gebauten Häusern. Hier kreuzen sich auch die vier großen Chausseen, die von Rezonville, Conflans, Metz und Ars sur Moselle zusammenlaufen. Um einem eventuellen Rückzug der französischen Hauptkräfte auf Verdun und einer Vereinigung mit der Heeresgruppe Châlons zuvorzukommen, überschritten preußische Truppen am 15. August südlich von Metz die Mosel. Es war der Geburtstag Napoleons I., der im zweiten Kaiserreich immer mit großem Pomp begangen wurde, was in diesem neuralgischen Moment des Krieges auf französischer Seite vielleicht zu einer gewissen Unaufmerksamkeit beigetragen haben mag. Bis zum späten

1 Louis-Ferdinand CELINE, Reise ans Ende der Nacht, Hamburg 1992, S. 104.

2 Von den Franzosen Borny-Noisseville genannt.

3 REGENSBERG, 1870/71, Bd. 2, S. 36.

${ }^{4}$ FAY, Tagebuch, S. $44 \mathrm{f}$.

${ }^{5}$ HIRTH, Tagebuch, Bd. I, S. 984. 


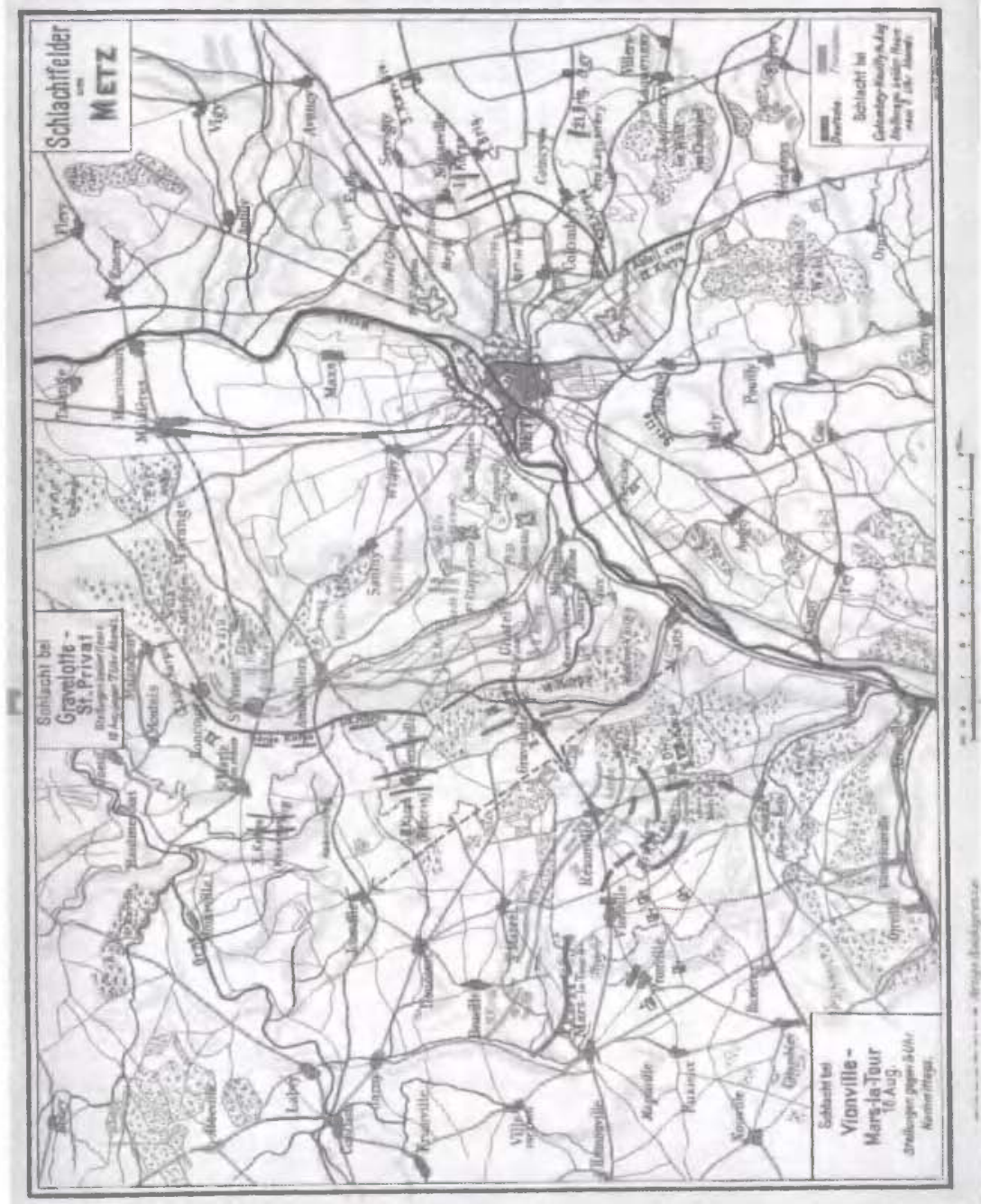

Abb. 6: Schlachtfelder um Metz. Quelle: Rigfnsberg, Bd. 2. 
Abend des 14. Augusts östlich von Metz kämpfend, mußte die Rheinarmee im Laufe des folgenden Tages durch die winklige, enge Stadt über die Mosel auf die Höhen westlich von Metz geführt werden, konnte also, so die Rechnung der Preußen, noch nicht allzu weit gekommen sein. Am Morgen des 16. jedenfalls schwenkte das III. brandenburgische Armeekorps, das die Festung südlich umgangen hatte, nach Norden in Richtung der alten Römerstraße $z$ wischen Metz und Verdun 6 ab und näherte sich so dem ahnungslosen Feind. Weder die deutsche noch die französische Kavallerieaufklärung vermochten es an diesem Tag, den genauen Standort des Gegners auszumachen. Gegen 9 Uhr stießen die Preußen, nachdem sie mühsam bergauf den westlichen Talrand der Mosel über Gorze erstiegen hatten, für beide Seiten völlig überraschend auf das Gros der Rheinarmee. Ihr kommandierender General von Alvensleben, der in der Hoffnung, wenigstens noch die Nachhut der abziehenden Rheinarmee erreichen zu können, auf zwei Wegen in Parallelkolonnen hatte vorrücken lassen ${ }^{7}$, ließ jetzt ohne zu zögern zum Gefecht aufmarschieren und eröffnete so die Schlacht von Vionville - Mars-la-Tour, die bei den Franzosen nach dem Örtchen Rezonville benannt ist. Das war eine spontane und auf keinerlei „abstrakte Generalstabskunst“ zurückzuführende Maßnahme, eine unter Zeitdruck getroffene Blitzentscheidung. Alvensleben wußte sehr bald, daß er allein gegen eine erdrückende Übermacht stand und bis zum Nachmittag mit Verstärkungen nicht rechnen konnte. Bis zur Ankunft des X. Armeekorps auf dem Schlachtfeld kämpften nun 30000 Preußen und Sachsen mit 114 Geschützen gegen eine Übermacht von 80000 Franzosen mit 306 Geschützen ${ }^{8}$. Trotz unterlegener Kräfte bestand Alvenslebens großer Vorteil zweifellos im plötzlichen und massierten Zugriff, also jener verwegenen Taktik, die Napoleon I. einst so unglaubliche Erfolge beschert hatte. Da sich aber keine schnelle Entscheidung abzeichnete, glich die Lage der Preußen so nach und nach jener der Engländer bei Waterloo, und Alvensleben soll in Anlehnung an Wellingtons klassischen Ausspruch geäußert haben, „er wollte, es wäre Abend oder das X. Armeekorps käme“9. Selbst wenn dies Legende ist, so traf es die Lage.

Den Hauptkampfplatz bildete die Vionviller Hochfläche, ein von Osten nach Westen und Südwesten abfallender, halbkreisförmiger Höhenzug, der durch die Mulden bei Flavigny, Vionville und Mars-la-Tour von Süden nach Norden durchschnitten ist. Dieses weite, zum Teil von Bächen durchzogene Brachfeld eignete sich zur Artillerieaufstellung im Schatten der langgezoge-

${ }^{6}$ Die Straße von Gravelotte über Vionville, Mars-la-Tour nach Verdun wird das Schlachtfeld vom 16. August teilen. Nördlich stehen die Franzosen. Von Süden her kommen die Preußen. Vgl. RegIensberg, 1870/71, Bd. 2, S. 53.

7 Ibid S. 49.

8 GolTz, Feldzug, S. 80. Die Zahlen schwanken, doch blieb das Kräfteverhältnis über den gesamten Schlachttag mindesten 2:1 zugunsten der Franzosen. Roth beziffert es auf 3:2. DERS., Guerre, S. 80.

9 STÄHLIN, Krieg 1870/71, S. 77. 
nen Rücken wie zur Entfaltung großer Kavalleriemassen ${ }^{10}$. Unter schwersten Verlusten hielten sich die Preußen im hin- und herwogenden Kampf, bis die Verstärkungen gegen $4 \mathrm{Uhr}$ nachmittags eintrafen. Moltkes militärstrategisches Diktum, wonach getrennt zu marschieren, aber vereint zu schlagen sei, hätte hier zur Katastrophe führen können. Bazaine aber zögerte und verschenkte so den Vorteil einer eindeutig günstigeren Positionen. Am frühen Nachmittag war auf deutscher Seite dennoch der kritische Moment erreicht und es drohte der Zusammenbruch. Manche Einheiten, die trotz Dezimierung und heftigsten Feuers nicht wankten, wurden regelrecht zusammengeschossen. Auf die Feuerkraft der Chassepotgewehre und Mitrailleusen, die dem Empfinden einzelner Betroffener nach „eine solche Masse von Kugeln aus-(schütteten), als wenn man mit der Gießkanne sprengt" 11 , war man nicht vorbereitet. Ein sächsischer Oberstabsarzt behandelte Verwundete,

mit 5-8 Schüssen. Auch ein Oberstleutnant von uns war mit Granatsplittern und Gewehrkugeln förmlich besät; 2-3 Verletzungen an einem Körper waren etwas sehr Häufiges ${ }^{12}$.

Verheerend wirkten vor allem aus der Nähe abgefeuerte Chassepot-Projektile, die bei kleinen Eintrittswunden laut Statistiken der Ärzte 7 bis $13 \mathrm{mal}$ größere Austrittswunden verursachten ${ }^{13}$ und so schwerste, in der Regel zum Tod führende Verletzungen verursachten.

Jetzt, als die Schlacht für die Deutschen fast verloren war, begannen die legendären Reiterkämpfe von Mars-la-Tour, die den Kampf bis zum Abend bestimmten. „Keine Form des Kampfes“, so ist bereits für die römische Epoche betont worden, „ist bewegter, dramatischer, imposanter als das Reitergefecht"14. Zunächst zersprengen preußische Husaren den Stab Bazaines, wobei dieser fast in Gefangenschaft gerät. Diesem Auftakt folgt die berühmte Reiterattacke der Brigade Bredow. Garde-Dragoner und Braunschweiger Ulanen müssen für ihre geschlagene Infanterie in die Bresche springen und die französischen Artilleriestellungen an den Büschen von Thronville angreifen. Generalmajor von Bredow zögert, weil er weiß, daß seine Leute ins sichere Verderben reiten sollen. Erst nach mehrfachen wütenden Befehlen aus dem Generalstab läßt er angreifen ${ }^{15}$. Die feindliche Artillerie samt Infanteriebedeckung wird unter zunächst noch geringen eigenen Opfern überritten, alles, was nicht fliehen kann, niedergehauen und niedergestochen. Die Pferde,

10 Vgl. REGENSBERG, 1870/71, Bd. 2, S. $53 \mathrm{f}$.

11 WILMOwski, Feldbriefe, S. $25 \mathrm{f}$.

12 Brief des sächsischen Oberstabsarztes Dr. Helbig vom 21. August 1870, in: Fürstlich-Schwarzburg-Rudolstädter Wochenblatt, Jg. 1870, S. 578. Aufschlußreich auch: Sanitäts-Bericht, Bd. III, Spezieller Theil I, S. 15-646 und Theil II, S. 843-1206.

13 Fischer, Kriegschirurgie, Bd. 1, S. 31.

14 JunkelmanN, Die Reiter Roms, S. 194.

15 Der Hinweis auf Auseinandersetzungen zwischen dem Generalstabschef des III. Korps Voigts-Rhetz und Bredow, der sich lange weigert, anzugreifen bei: KRETSCHMAN, Kriegsbriefe, S. 87. 
wie wahnsinnig im Gebrüll der Schlacht, trampeln Gestürzte und Verwundete zu Tode. In rasendem Tempo geht es weiter, bis französische Kavallerie den preußischen Spitzen in die Flanken fährt. Die Vorderen wenden sich um, reißen die nächsten mit sich fort, stürmen unter schwersten Verlusten stechend, hauend und schießend zurück. Durch französisches Granat- und Gewehrfeuer zudem entscheidend dezimiert, verliert die Brigade mehr als die Hälfte ihres Bestandes und ist nicht mehr gefechtsfähig ${ }^{16}$. Doch wird so kostbare Zeit gewonnen, die es braucht, bis das X. Armeekorps rettend eingreifen kann. Dessen Anführer Prinz Friedrich Karl, dem so die Früchte des von ihm nicht errungenen Erfolges zufallen, befiehlt noch, obschon die Würfel gefallen sind, „des moralischen Eindrucks halber einen letzten Vorstoß auf der ganzen Linie"17. Nochmals fließt viel Blut. Auch sachlich-kritischen Beobachtern wurden diese Ereignisse zum Symbol deutscher Einheit auf dem Schlachtfeld und jener Kameradschaft, die „neben den Brandenburgern auch Westfalen und Hannoveraner, Ostfriesen und Oldenburger, Rheinländer, Thüringer, Hessen und Schlesier" ruhmreich zusammen streiten ließ ${ }^{18}$. Über die später zum „Todesritt“ mythisierte Attacke Bredows und seiner Reiter berichtet ein Unterführer:

Zuerst sollte von jedem Regimente eine Eskadron sich dem sicheren Tode weihen. Ich ließ loosen, Rittmeister von Wuthenau mit der 3. Eskadron zog das Loos zu seinem Heile, die Eskadron wurde seitwärts dirigiert und bekam nur Feuer ohne Menschen zu verlieren. Nun wurden die drei anderen Eskadrons meines Regiments und drei UlanenEskadrons zur Erstürmung beordert [...] Jeder von uns aber konnte sich sagen, daß Gottes Gnade allein ihn bewahrt, denn von den elf Zügen, die ich hineingeführt [...], brachte ich noch drei zurück; daß soviel noch herausgekommen, ist ein Wunder, eigentlich konnte keiner darauf rechnen ${ }^{19}$.

Alvensleben hat dazu rückblickend bemerkt, daß das Auslosen „ein Unikum in der Kriegsgeschichte seit den Horatiern" gewesen sei ${ }^{20}$. Im Kaiserreich begann man den Opferritt bald in den höchsten Tönen zu glorifizieren. Freiligrath schrieb voller Emphase sein Gedicht Die Trompete von Gravelotte und verwechselte dabei die Orte des Geschehens ${ }^{21}$. Der Umstand, daß beide Söhne Bismarcks an der Attacke teilnahmen und verwundet wurden, verdichtete die mythische Substanz des Stoffes noch zusätzlich. Emil Hünten malte die Schlachtszenerie 1878 für Bismarck persönlich. Wilhelm von Bismarck reitet mit erhobenem Säbel im Vordergrund, sein Bruder Herbert ist

16 KaEHLER, Reiterei, S. 30. GOTTBERG, Kavallerie, S. 170-173.

17 Vgl. STÄHLIN, Krieg 1870/71, S. 78.

18 REGENSBERG, 1870/71, Bd. 2, S. 59.

19 Brief des Majors von Schmettow vom 18. August 1870, in: HD, S. 1526. Von den 800 Beteiligten blieben 379 Mann tot, verwundet oder vermißt auf dem Schlachtfeld. Der Deutsch-Französische Krieg, Bd. I, S. 588.

20 Zit. nach REGENSBERG, 1870/71, Bd. 2, S. 68.

21 Vgl. FreILIGRATH, Werke, Bd. II, S. 268. 
hinter dem Regimentskommandeur Oberst von Auerswald in der Bildmitte zu sehen ${ }^{22}$.

Im Taumel der großen Erinnerungen schwand der Sinn für das Wirkliche, und es fehlte die Sensibilität für den sich rasch vollziehenden strukturellen Wandel. Man antizipierte nicht den selbstmörderischen Charakter derartiger Unternehmen im angebrochenen Zeitalter der Schnellfeuerwaffen. Vor Metz zeichnete sich dies bereits deutlich $\mathrm{ab}$. Noch entschied hier freilich neben der Infanterie auch die Kavallerie den Kampf, noch fehlten Stahlhelme und Panzer. Alte Ordnungsmuster spiegelten sich, wenn die Elite des Heeres auf dem Rücken der Pferde saß, hoch zu Roß, weit über dem Fußvolk. Pferde spielten zumindest in den Köpfen noch immer eine wichtige Rolle, blieben ein Attribut der Überlegenheit. Besonders in Ostpreußen, dem Land der Pferdezucht, hatte man sie über lange Zeiten gezüchtet und zur Belebung, wie En-

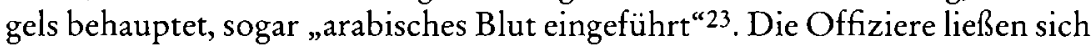
die Tiere kommen, vorführen und zureiten, wechselten sie, wenn sie unzufrieden waren, wußten freilich auch, was sie ihnen zu danken hatten. So hieß es bei Kretschman nach Mars-la-Tour resümierend:

Ich glaube, daß man es mir als Verdienst anrechnet, in einem kritischen Momente 48 Geschütze auf eine Höhe geführt zu haben, von der aus das Vorgehen des Feindes unmöglich gemacht wurde. Das Verdienst gebührt aber mehr meinem Wallach, der allerdings, als die Sache zu Ende war, nicht einen Schritt mehr gehen konnte ${ }^{24}$.

Lanzentragende Reiter, sogenannte Ulanen, wirkten vor allem in der Formation achtungsgebietend und furchteinflößend. Ihre Ausbildung war artistisch, ein fast zirkusreifer Schliff, vieles davon langwierig, aber praktisch längst ohne Wert ${ }^{25}$. Wo es ging, wurde die Kavallerie geschont, auch wenn die Infanterie litt. Der Mythos und das Selbstvertrauen der alten Panzerreiterei lebten in ihr fort. Für die Franzosen waren die Ulanen das Urbild des furchterregenden und todbringenden Feindes aus dem Osten. Man nannte sie auch Hurlans, solche also, die wie Wölfe heulen - drohend und blutrünstig. Nach Reichshofen und Mars-la-Tour rühmte man noch auf beiden Seiten die Stärke der Reiterei, doch hätte bereits die Erfahrung dieser Kämpfe lehren können, daß den technischen Waffengattungen, vor allem der Artillerie, die Zukunft gehörte.

Durchaus verbietet es sich, den „kleinen Kürassier von Reichshofen“ dem

22 Original im Bismarck-Museum in Friedrichsruh.

${ }^{23}$ Zum Vorzug des ostpreußischen, auch nach dem Gestüt Trakehnen benannten Pferdes meint Engels an anderer Stelle noch weiter, daß dieses „zwar an Größe und Schnelligkeit dem englischen Kavalleriepferd unterlegen“, jedoch ein „weit besseres Kriegspferd“ sei und "in einem Feldzug fünfmal soviel aushalten “ könne. ENGELS, Aufstieg und Niedergang von Armeen. In: MEW, Bd. 17, S. 96-100, hier S. 99.

24 KrETSCHMAN, Kriegsbriefe, S. $79 \mathrm{f}$.

25 Noch mein Großvater, der 1939/40 in Ostpreußen zum berittenen Funktruppführer ausgebildet wurde, erzählte von seinem Vorgesetzten, einem Pferdenarr und auf die klassische Reitschule erpichten Oberst, der schon im Ersten Weltkrieg Kavallerist und dann in Friedenszeiten Zirkusdirektor gewesen war. 
„Ritter von Bouvines“26 gleichzusetzen, doch ist der Krieger zu Pferde damals noch immer und weiterhin ein Symbol militärischer und gesellschaftlicher Überlegenheit, sein Sozialprestige bleibt riesengroß. Auch im Kaiserreich ändert sich daran nichts: Die „aristokratisch-hierarchisch mächtige Kavallerie läßt sich nicht auf die neuen Sachnotwendigkeiten reduzieren “27. Die Arroganz eines ganzen Standes spiegelt sich darin. In einer SimplicissimusKarikatur Eduard Thönys von 1911 reiten zwei Kavalleristen an einer Gruppe Landarbeiter vorbei und es entspinnt sich folgendes Gespräch: „Schrecklich, so 'n armer Kerl, der von seiner Händ Arbeit leben muß!“ "Immer noch besser wie Infanterist, der muß von seiner Füße Arbeit leben." Die Vergötterung der Kavallerie wirkte bis in die Volksschullesebücher hinein, wo etwa der Buchstabe „U“ durch den Begriff „Ulan“ erläutert wurde². Daß eine in Formation herankommende berittene Einheit gehörigen Eindruck machen mußte und noch macht, steht dagegen außer Zweifel. Wer einmal die Militärparade zum Nationalfeiertag Frankreichs in Paris erlebt hat, weiß, welche Bewunderung die über die Avenue des Champs Élysées in strenger Ordnung anreitenden Eskadronen mit ihren vom Pflaster mächtig widerhallenden Hufschlägen auch dort noch immer hervorrufen. Von den schlachtentscheidenden Ritten á la Seydlitz bei Roßbach war man indes bereits 1870 entfernt, und später, im Ersten Weltkrieg, endeten die vor allem von den Russen immer wieder nach vorn gebrachten Kavallerieregimenter als lebendige Kugelfänge ${ }^{29}$ im Sperrfeuer der Maschinengewehre.

Der Kampf des 16. August endete am Abend mit einem Patt und dem Stillstand der gesamten Rheinarmee bei Metz. In mondheller Sommernacht kampierten die erschöpften Truppenmassen einander dicht gegenüber. Beide Seiten erklärten sich zum Sieger, indem sie den Besitz des Schlachtfeldes anzeigten. Aber darum ging es nicht. Vielmehr zählte der Tempoverlust, der die Formierung und Massierung der französischen Kräfte um die Festung behinderte und einen Rückzug auf Verdun unmöglich machte. Wie schon bei Borny hatten also vor allem die Franzosen nichts gewonnen. Da sie sich ebensowenig zu einem jetzt noch möglichen Abmarsch nach Norden entschlossen und die angestrebte Vereinigung mit Mac-Mahon und Napoleon ohnehin bereits unmöglich geworden war, kam das Ergebnis der Schlacht für sie einer Niederlage gleich. Ungeachtet dessen beglückwünschte der Kaiser Marschall Bazaine zu seinem Erfolg und bedauerte, nicht dabeigewesen zu $\operatorname{sein}^{30}$. Bazaine, der es besser gewußt haben mag, sah sich nun gezwungen, noch weiter auf Metz zurückzugehen und den deutschen Hauptkräften mit seiner gesamten Streitmacht entgegenzutreten. Daß dabei auch Unmengen an

26 Duby, Sonntag, S. $11 \mathrm{f}$.

27 NiPPERDEY, Deutsche Geschichte, Bd. II, S. 228.

28 JaRosChKa, Untertan, S. 14.

29 GotTberg, Kavallerie, S. 174.

30 „Je vous félicite de votre succès, je regrette de ne pas y avoir assisté.“ BAZAINE, L'Armée, S. 61. 
Proviant verloren gingen, die wegen mangelnder Transportkapazität zum Teil sogar verbrannt wurden ${ }^{31}$, war angesichts der weiteren Entwicklung ein doppelt folgenschwerer Verlust.

Nachdem die Waffen am 17. August geschwiegen hatten, kam es tags darauf zur Schlacht bei Gravelotte-St. Privat, der größten und möglicherweise entscheidenden des ganzen Krieges ${ }^{32}$. Die großen Schlachten vom 14., 16. und dann vom 18. fanden im Rhythmus von zwei Tagen statt - mit dem Minimum an Pause also, um die Truppen wieder kampfbereit zu machen. Um 5 Uhr morgens begann der deutsche Aufmarsch; in einem weiträumigen Rechtsschwenk rückten die Truppen auf breiter Front gegen Metz vor. Die Schlachtaufstellung der beiden Heere war also seitenverkehrt, so daß der deutsche Angriff in östlicher Richtung vorgetragen wurde, während die Verteidiger ihre Kräfte gegen Westen entfalteten. Die Stellungen zwischen Roncourt, St. Marie aux Chênes und St. Privat im Norden sowie Gravelotte und St. Hubert im Süden boten den Franzosen durchaus günstige Aussichten auf eine erfolgreiche Verteidigung. Rein numerisch kamen neun Verteidiger auf jeden Schritt ${ }^{33}$, wobei Dörfer und Gehöfte als Knotenpunkte innerhalb der Stellung von Avant-Garden, Eliteeinheiten, wie man modern sagen könnte, besonders stark besetzt waren. Hinter den Verteidigungslinien jedoch fiel das Terrain steil ins Moseltal ab, was ein Manövrieren mit zurückgehaltenen Reserven fast unmöglich machte und bei einem Mißerfolg nur die Rückzugsmöglichkeit nach Metz offen ließ. Damit drohte die Einschließung der Rheinarmee nun ganz unmittelbar. Zunächst war die Lage wieder unübersichtlich. Deutscherseits wußte man nicht, wohin der Feind abgezogen war. Auch kamen sich die vorrückenden Truppen zum Teil selbst in die Quere, so daß der Vormittag verstrich, ehe die Schlacht begann. Der erste Kanonenschuß fiel um 12 Uhr. Überall auf dem Schlachtfeld stiegen Explosionswolken in die Höhe, Truppenverbände eilten den Kampfplätzen zu. Angst und Feigheit waren verpönt, denn sie widersprachen einem soldatischen Männlichkeitsideal, zu dem konstitutiv bereits in Friedenszeiten die Duldung von Gewalt durch Vorgesetzte oder ältere Kameraden gehört hatte ${ }^{34}$. Doch ahnte mancher, daß ihn nun nicht mehr nur Prügel erwartete, als er nach der Hölle von Mars-la-Tour erneut ins Feuer sollte:

Der Mensch heulte vor Angst und wir ließen ihn verachtungsvoll liegen. Nach zwei Stunden wurde er uns zum Verbandsplatz gebracht, noch immer unverwundet, aber mit röchelndem Athem und offenen Augen, die, wenn man mit dem Finger den Aug-

31650000 Portionen Lebensmittel und 200000 Rationen Hafer. Vgl. RegENSBERG, 1870/71, Bd. 2, S. 84.

32 BRONSART, Kriegstagebuch, S. $43 \mathrm{f}$.

33 HANNEKEN, Krieg um Metz, S. 14.

34 Vgl. FreverT, Schule der Männlichkeit, S. 172 f. 
apfel faßte, nicht zwinkerten; er starb kurze Zeit darauf, der erste Mensch, den ich aus Angst habe sterben sehen ${ }^{35}$.

Man kann sich denken, daß dies kein Einzelfall war, doch zählt die Passage im Brief eines Arztes aus der bekannten Jenaer Theologenfamilie zu den seltenen Hinweisen auf die Verweigerung des Kampfes. Derlei Versagen blieb in der Erinnerung tabu und für die Betroffenen, so sie überlebten, ein negatives Stigma.

Anfangs noch forsch angreifend, stoßen die Deutschen bald auf zähe französische Gegenwehr. Hitze, Staub und Wassermangel erschöpfen die Angreifer. Um das Dorf St. Privat tobt ein besonders erbitterter Kampf. Den Gipfel des feindlichen Höhenrückens bildend, mit massiven Häusern bestückt und von hohen Mauern umschlossen, ist es das festeste Bollwerk der Verteidiger $^{36}$. Hier erleiden die Angreifer infolge vieler mißglückter Sturmangriffe über die nackten, leicht ansteigenden Felder besonders hohe Verluste. An die 8000 Preußen fallen dem vernichtenden Feuer der französischen Chassepotgewehre zum Opfer, deren Läufe, aus Mauerbreschen und Häuserruinen starrend, Tod und Verderben über die Angreifer bringen. Den preußischen Zündnadelgewehren in Reichweite, Treffsicherheit und Feuergeschwindigkeit überlegen, bringen sie die preußischen Angriffswellen immer wieder zum Stehen. Die Schützenlinien der Angreifer lösen sich bald in ungeordnete Haufen auf, die Schreie der Führer und das wilde Gedröhn ihrer Hörner und Trommeln treibt die Front indes weiter und weiter nach vorn ${ }^{37}$. Todesmutige Offiziere eilen ihren im Feuer mit eingezogenen Schultern und gesenkten Köpfen oft zögernden Männern - zum Teil geht man provozierend hochaufgerichtet und weigert sich, in Deckung zu gehen ${ }^{38}$ - voran, wobei die Unteroffiziere, wie schon in früheren Kriegen jedes Zurückweichen und Stehenbleiben notfalls mit Waffengewalt unterbinden. Von einem freiwilligen und fröhlich-opferwilligen Vorgehen der Mannschaften kann also durchaus nicht die Rede sein. Marschall Canrobert, der die Verteidigung leitet, traut indes seinen Augen nicht, als die Angreifer trotz der ungeheuren Verluste ihre Reihen immer wieder zu schließen vermögen.

Wiederum, wie schon am 16. August, treffen zwei Konzeptionen militärischer Führung aufeinander. Die Preußen, mächtig und oft ungestüm vorwärts drängend, stoßen auf eine kontrollierte französische Defensive, deren nie erlahmende Feuerkraft empfindliche Lücken in die Reihen der Angreifer reißt. Alvensleben hatte rückblickend auf Mars-la-Tour noch am Morgen des 18. auf die Unmöglichkeit hingewiesen, „mit unserer auf den Exerzierplätzen eingeübten Taktik (Lineartaktik M. S.) vorwärtszukommen“, und betont, daß man vor jedem Sturm unbedingt „die Artillerie lange und nachhaltig wir-

35 HaSe, Feldarztbriefe, S. 13.

36 ARnOLD, Die Preußischen Garden, S. 49.

37 KeEgan, Antlitz, S. $45 \mathrm{f}$.

38 FunCK, In den Tod gehen, S. 239. 
ken lassen" müsse ${ }^{39}$. Damit war das Prinzip der Feuerwalze antizipiert, jenes flächendeckenden und vernichtenden Artilleriebeschusses, wie er im Verlauf des Ersten Weltkrieges perfektioniert wurde, um tief gestaffelte Grabensysteme der Verteidiger vor Beginn eines Angriffes zu zerstören und deren Abwehrkraft so entscheidend zu schwächen. Gerade dieses aber war, als die Garde gegen 5 Uhr nachmittags zum Sturm auf St. Privat antrat, nicht geschehen. Divisionskommandeur General von Pape, der den Befehl dazu von Prinz August ${ }^{40}$ erhielt, verwies auf den Umstand, daß auf das Dorf noch kein Kanonenschuß gefallen war und zudem der unterstützende Angriff des XII. (sächsischen) Armeekorps von Norden her bevorstand. Der Prinz schnitt ihm das Wort ab und forderte ungehalten: „Jetzt greifen sie mit der Division St. Privat an und nehmen sie es weg! [...] - und nun machen sie nur, das dau-

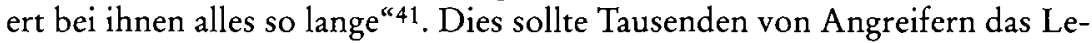
ben kosten.

Fast unglaublich erscheint mit heutigem Abstand der Drang, Fahnen und Banner noch in aussichtsloser Lage zu behaupten oder gar zu erobern. Ein solcher Opfermut der Ehre halber, den es sicher nicht massenhaft, aber eben doch gab, bleibt dem Nachgeborenen unfaßbar. Ritualisierte Sterbeszenen stehen damit in Zusammenhang. Der spektakuläre Tod unter der Truppenfahne als Symbol der Ehre und Zeichen autonomer Regimentsherrlichkeit erfolgte auch stellvertretend für den Stand ${ }^{42}$. Dieser wahnwitzige Fahnenkult wurde dann in Friedenszeiten durchaus massenwirksam und bildete ein konstituierendes Element der „Nation in Waffen“. Als am Neujahrstag 1900 Kaiser Wilhelm II. im Berliner Zeughaus das Militär um seine Feldzeichen geschart, vor dem „Herrn der Heerscharen" kniend und vor Gott sich beugen sah, genügte ihm dafür ein Blick auf die neu zu weihenden Fahnen des Gardekorps als Erklärung, „denn sie verkörpern unsere Geschichte“43.

Gerade die Garderegimenter waren es, die beim Sturm auf St. Privat den höchsten Blutzoll erbracht hatten ${ }^{44}$. Die Verteidiger des Dorfes sahen sich am Abend von Westen und Norden attackiert, leisteten aber noch immer verbissen Widerstand. Erst im Gemetzel eines grauenvollen Nahkampfes entschieden sich die Dinge:

39 RegensberG, 1870/71, Bd. 2, S. 117.

40 General der Kavallerie Prinz August von Württemberg - Oberbefehlshaber des Garde-Korps, das der Zweiten Armee unter Prinz Friedrich Karl von Preußen unterstellt war.

41 Es scheint, als habe tatsächlich der Ehrgeiz, zuerst, also vor den Sachsen, St. Privat zu nehmen, den Ausschlag für den Angriffsbefehl gegeben. RegensBERG, 1870/71, Bd. 2, S. 117.

42 FUnCK, In den Tod gehen, S. $228 \mathrm{f}$.

43 Zit. nach VOGEL, Nationen, S. 83.

44 Von 21200 Mann verlor das preußische Gardekorps an jenem Nachmittag 307 Offiziere und 7923 Soldaten an Toten und Verwundeten. REgensBerg, 1870/71, Bd. 2, S. 119. 
Die Preußen rannten wie wütend auf uns los, wir marschierten fest gegen sie, ich verlor die ruhige Besinnung und weiß heute noch nicht, wie ich herauskam, als ich mich zuletzt allein sah. Ich war wie wahnsinnig und hatte dichten Schaum vor dem Mund [...] Wir stachen eben hinein, wie es kam, es war ein ganzer Klumpen Franzosen und PreuBen durcheinander, und ich habe vielleicht auch manchen Franzosen erstochen ${ }^{45}$.

Eng beieinander sah man die Leichen von Freund und Feind liegen, als der letzte Schuß gefallen war und sich die Pulverschwaden über dem Trümmerfeld verzogen hatten. So wie sich der ohrenbetäubende Lärm der Schlacht gelegt hatte, wurden die Klageschreie und das Wimmern der Verwundeten vernehmbar. Wenn diese bei Gravelotte und St. Privat auch, wir werden auf die Logistik der Verwundetenbetreuung gleich noch näher eingehen, vergleichsweise rasch grundversorgt und abtransportiert werden konnten, so läßt sich deren Elend doch kaum mit Worten beschreiben. Langsam kamen auch die Überlebenden wieder zu sich. Wie verklärend mutet dagegen die Rückschau Paul von Hindenburgs an, damals Unterleutnant beim 3. Garderegiment zu Fuß:

Es ist ein unbeschreiblich ergreifender Augenblick, als sich bei sinkender Abendsonne unsere vordersten Kampflinien zum letzten Vorbrechen erheben. Kein Befehl treibt sie an, das gleiche seelische Empfinden, der eherne Entschluß zum Erfolg, ein heiliger Kampfesgrimm drängt nach vorwärts. Dieser unwiderstehliche Zug reißt alle mit sich fort. Das Bollwerk des Gegners stürzt bei Einbruch der Dunkelheit. Ein ungeheurer Jubel bemächtigt sich unser ${ }^{46}$.

Das war 1920. Es wird später am Beispiel der großen Ausfallschlacht bei Noisseville noch zu fragen sein, was der von Hindenburg sogenannte „eherne Entschluß zum Erfolg“ und der "heilige Kampfesgrimm“ über die Zwangslage von Befehl und Gehorsam hinaus für den Einzelnen tatsächlich bedeuteten. Bis zum Abend sahen sich die Franzosen aus den wichtigsten Positionen verdrängt. Vor allem hatte wiederum die schwere Artillerie den Kämpfen das Gepräge gegeben. St. Privat und Amanviller lagen am anderen Morgen vollkommen zertrümmert von preußischen Kanonen. Zuletzt waren hier Freund und Feind in die Schußlinien geraten und vernichtet worden. Wiederum erinnern die Berichte an Bilder von Trümmerlandschaften des Ersten Weltkrieges, an die völlig verwüsteten Gegenden an der Somme oder in Flandern:

Heute morgen ritt ich nach der Stelle, die wir beschossen (2 Häuser mit Schützengräben) und hatte daselbst die Genugthuung, über wirkliche Berge von Leichen hinwegzureiten, die Häuser waren wie ein Sieb durchlöchert, eine feindliche Batterie ganz zerschossen. Das alles hatte meine Batterie gethan! Es ist entsetzlich, fürchterlich! Unsere armen braven Leute, die tapferen Kameraden, Alles, Alles dahin, Alles todt, vernichtet, gräßlich verstümmelt! Ich schäme mich ordentlich, noch zu leben ${ }^{47}$.

45 Brief eines Elsäßers, in: HiRT'H, Tagebuch, Bd. I, S. $917 \mathrm{f}$.

${ }^{46}$ HindenBURG, Leben, S. 35. Gemeint ist der gegen 19.30 Uhr einsetzende gemeinsame Sturm der Preußen und Sachsen. Nach einer Stunde ist St. Privat in den Händen der Deutschen, die dabei 2300 Gefangene machen. REGENSBERG, 1870/71, Bd. 2, S. 119. 47 Brief eines preußischen Offiziers nach Gravelotte, in: WZ, Jg. 1870, Nr. 202/Blatt 1. 


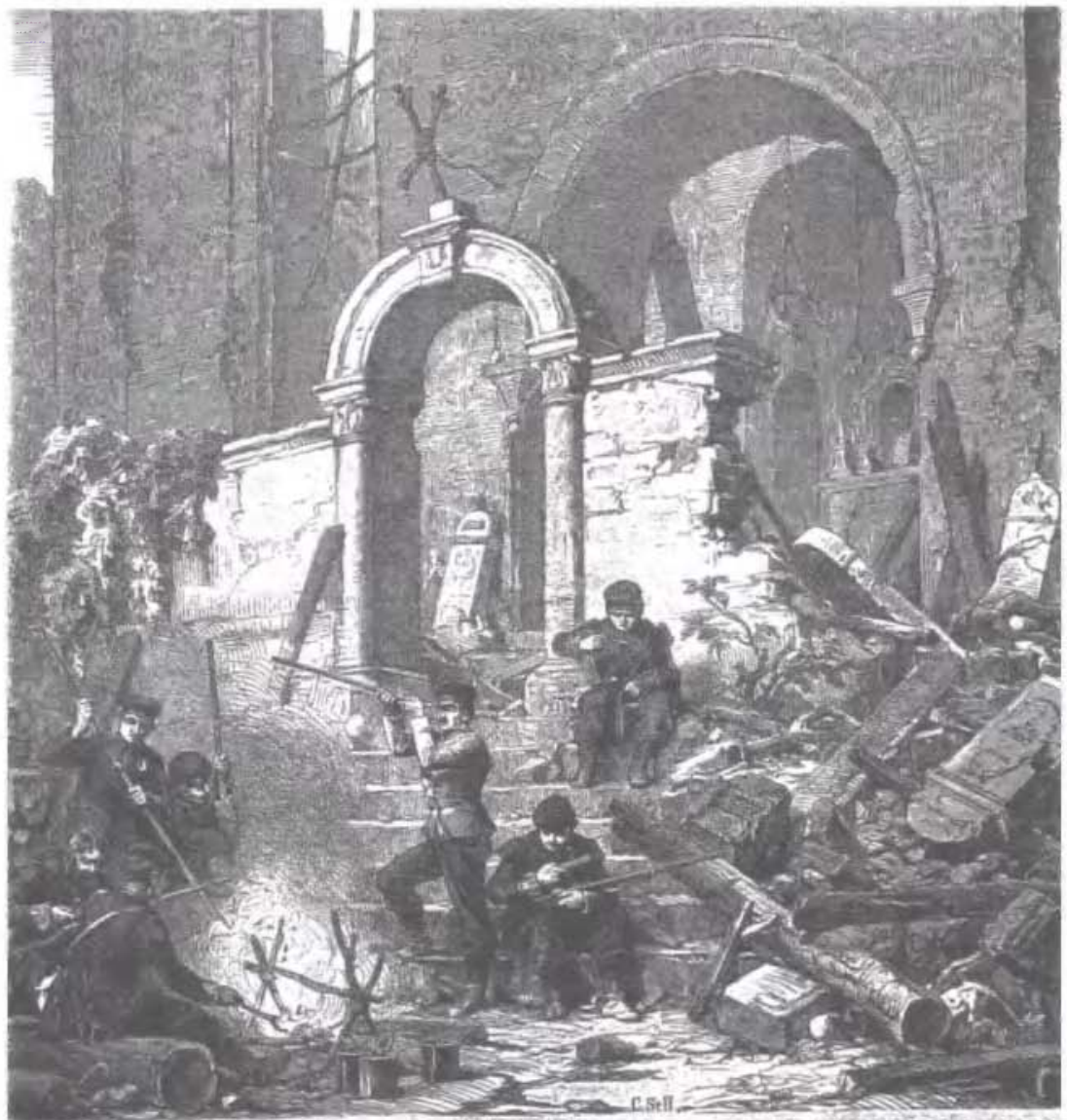

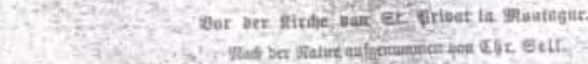

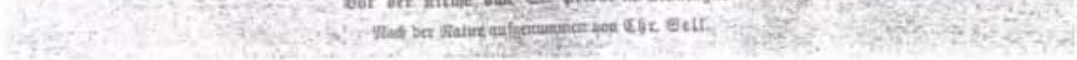

Abb. 7: Vor der Kirche von St. Privat in Montague. Quelle: Gartenlaube (1870), Nr. 47. 
Daß man sich im Moment der Besinnung nach überstandener Schlacht "schämte, noch zu leben", spiegelt die verbreitete Annahme, durch den eigenen Tod, den Heldentod eben, eine Art sittlicher Prüfung zu bestehen. $\mathrm{Zu}$ dem ging es mit Gottes Segen um die Ehre der Armee, für die man mit Leib und Leben einstand ${ }^{48}$. Dabei taugten wiederum Vorbilder aus der Zeit der Befreiungskriege, um eine opferbereite Männlichkeit zu sakralisieren und der zivilen Welt den streng militärischen Charakterzug entgegenzustellen ${ }^{49}$. Zur schweren Verwundung eines befreundeten Offiziers vermerkte Kretschman dementsprechend:

Er hat einen Schuß im Unterleib - die schmerzhafteste und meist tödlichste Verwundung. Leute wie Prittwitz, in deren Charakter die Bestandteile zum Heroismus liegen, die, ich möchte sagen, meist zwischen Himmel und Erde marschieren, scheinen von der Vorsehung bestimmt zum Untergange so oder so. Im gewöhnlichen Lauf der Dinge gehen sie etwa durch Verliederung oder praktische Unbrauchbarkeit zugrunde - im Kriege fallen sie, weil dann eine Art Begeisterung über sie kommt, die alle Rücksichten der Klugheit hintenan setzt. Prittwitz hatte ein Stück Körnernatur. Gott gebe ihm, soll's sein, ein gleiches Ende, lieber ein langes Leben ${ }^{50}$.

Fast schon als schmählich mußte unter solchen mentalen Dispositionen eine Gefangennahme durch den Gegner empfunden werden. Noch in Ernst Jüngers autobiographischem Jugendroman Afrikanische Spiele von 1936, also bei der Enkelgeneration, findet sich eine in diese Richtung bezeichnende Passage. Während der Pennäler seinen Plan ersann, nach Frankreich zu entfliehen und dort in die Fremdenlegion einzutreten, bereitete ihm die Vorstellung, "daß man an der Grenze vielleicht auf mich schießen würde ebensoviel Vergnügen“, wie ihn andererseits „die Aussicht beunruhigte, daß mich irgendein gutmütiger Zöllner in aller Gemütlichkeit festnehmen und abliefern könnte" 51 .

Angesichts der Opfer, die die Schlachten gefordert hatten ${ }^{52}$, schrieb der preußische König nach Berlin, daß er sich scheue, nach Verlusten zu fragen und Namen zu nennen ${ }^{53}$ und beklagte sich bitter darüber, daß seine höheren Offiziere alles Manöverwissen vergessen hätten und „wie toll“ drauf los gegangen wären. Ein solches Schlachten könne man nicht lange aushalten ${ }^{54} . \mathrm{Ob}$

48 JEISMANN stellt den Unterschied zu 1813 heraus, als die Vorstellung vom „Tod fürs Vaterland" viel stärker mit dem Motiv des Nationalen verbunden war. Ders., Vaterland, S. 256.

49 Vgl. SChiLling, Konstruktion, S. 135-137.

50 KRETSCHMAN, Kriegsbriefe, S. 261.

51 JÜNGER, Afrikanische Spiele, S. 24.

52 Die Franzosen verloren am 16. und 18. August 29700, die Deutschen sogar 36000 Mann: Bazaine, L'Armée, S. 214f. HelmerT, Usczek, Preußischdeutsche Kriege, S. $216 \mathrm{f}$. ROTH beziffert die Gesamtverluste von Borny bis St. Privat auf annähernd 75000 Tote, Verwundete und Vermißte. DERS., Guerre, S. 92.

53 Kaiser Wil.helms Briefe, Bd. II, S. 277.

54 Tagebücher des Generalfeldmarschalls von BLumENTHAL, S. 82. Die hohen Verluste der Augustschlachten weisen in ihrer Tendenz wiederum auf den Ersten Weltkrig hin, der - so wie bei Gravelotte und St. Privat - durch Frontalangriffe stark befestigter Stel- 
er wußte, wer den selbstmörderischen Angriff der Garde auf St. Privat zu verantworten hatte? Für das Offizierskorps gab es kein Ersatzbataillon. Im kritischen Rückblick ist für diese erste Phase des Krieges auch betont worden, daß der glückliche Ausgang der Schlachten nicht nur der Tapferkeit der eigenen Truppen zu danken war, sondern noch weit mehr den Fehlern der französischen Generale ${ }^{55}$. In der "Gartenlaube“ fanden sich emphatische Zeilen, deren Klänge uns später, im Langemarck-Mythos von 1914, ganz ähnlich wieder begegnen:

„Die Wacht am Rhein“" war das Kampflied der Garde geworden; unter dessen Klängen stürmten sie die Anhöhe hinan, das deutsche Lied war der Franzosen Grabgesang bei St. Privat ${ }^{56}$.

Wer es ausprobiert hat, weiß, wie unmöglich es ist, gleichzeitig zu singen und schnellen Schrittes bergan zu marschieren oder gar zu stürmen. Hans $\mathrm{Ca}$ storps jämmerlich endender Versuch an den Hängen des Zauberberges ist der schöne literarische Beleg dafür.

An vielen Stellen dauerte der Kampf bis in die Nacht. Doch wichen die Truppen der Rheinarmee jetzt langsam ins Moseltal zurück und bezogen im Schutz der Festungswerke Position. Ungeheure Militärmassen, zum Teil demoralisiert, zum Teil noch in guter Ordnung, wälzten sich nun langsam auf die Stadt und drohten jedes zivile Leben zu ersticken. Zunächst noch mit einem weiteren Entscheidungskampf rechnend, erließ das deutsche Oberkommando im Laufe des 19. August die Befehle zur Blockierung von Metz. In Frankreich herrschte Ungewißheit über das Resultat der Schlachten. Unsichere Meldungen, Berichte über Teilerfolge bei Borny und Rezonville-Marsla-Tour kursierten, aber seither meldete sich Bazaine nicht mehr ${ }^{57}$. Der Niederlage und der prekären Lage vor allem schien man sich selbst innerhalb der Armeeführung noch immer nicht voll bewußt zu sein. Die zuversichtlichen, von nahezu intakten Einheiten handelnden Rapports der Korps-Kommandanten an Bazaine zeugen davon ${ }^{58}$. Während man französischerseits davon überzeugt blieb, nicht geschlagen worden zu sein, fehlten zumindest in den deutschen Augenzeugenberichten die Siegeseuphorie und der Jubel, wie sie etwa nach Wörth und vor allem nach Sedan vorherrschten. Hier handelte es sich offenbar nicht nur um die klareren Siege, sondern eben auch um weit weniger verlustreiche Kämpfe. Verbreitet wurde indes das Bild des preußischen Königs, wie er am Abend des 18. Augusts im Licht der Wachfeuer auf dem Schlachtfeld die Siegesdepesche an Königin Augusta diktiert und damit

lungen und durch ein sehr aggressives Vorgehen der Infanterie geprägt war. Vgl. KüHLICH, Soldaten, S. 402.

$55 \mathrm{Vgl}$. REgENSBERG, 1870/71, Bd. 2, S. $36 \mathrm{f}$.

56 Gartenlaube (1870), Nr. 40, S. 655.

$57 \mathrm{Vgl}$. Roth, Guerre, S. 87 f.

58 B AZAINE, L'Armée, S. 216-222. 
gleich einem mittelalterlichen Herrscher durch persönliche Anwesenheit im Zentrum der Wallstatt den Sieg seiner Truppen symbolisierte ${ }^{59}$.

Obgleich die militärische Belagerung der Festung erst jetzt begann, stand sie doch in unmittelbarer Beziehung zu Verlauf und Ergebnissen der schweren Kämpfe zwischen dem 14. und 18. August 1870. Allein die Tatsache, daß nun die stärkste Feldarmee des französischen Kaiserreiches nahezu hoffnungslos eingeschlossen war, schwächte die Verteidigungsfähigkeit Frankreichs entscheidend und ließ die Siegeshoffnungen weiter sinken. Ohne Bazaines rettenden Erfolg, soviel stand fest, würden sich Napoleon III. und sein Kaisertum kaum noch lange halten können. Unmittelbar prägten die Resultate der Kämpfe den Alltag der Belagerer. Die Betreuung Verwundeter und Sterbender, die massenhaften Beerdigungen von Gefallenen, das Aufräumen der Schlachtfelder, die wegen der völlig verwüsteten Gegend auftretenden Verpflegungs- und Nachschubschwierigkeiten und schließlich der Zwang, zwischen verfaulenden Leichen und Pferdekadavern unter freiem Himmel biwakieren zu müssen - all dieses bestimmte das Befinden der Soldaten und wurde mitunter bedrückender empfunden als das Erleben der Schlacht selbst.

\section{Verwundete, Totengräber und Totenkult}

Die vielen tausend bei Mars-la-Tour und Gravelotte Verwundeten befanden sich in keiner günstigen Lage. Diejenigen, die sich aus eigener Kraft hatten retten können, schienen dem Schlimmsten entgangen zu sein und durften hoffen. Doch liefen auch die Leichtverletzten immer Gefahr, an Wundbrand oder Blutvergiftung - Komplikationen, gegen die es damals noch keine Mittel gab - zu sterben. Krüppelheere, wie sie der Erste Weltkrieg hervorbringen sollte, fehlten nach 1871 nicht etwa, weil es weniger Verwundete gegeben hätte, sondern weil diese eben noch eine weitaus geringere Überlebenschance hatten. Eine konsequent antiseptische Wundbehandlung setzte sich in den Operationssälen erst nach 1892 durch $^{60}$. Daher, obschon es an Betroffenen nicht fehlte, wurde die „rosarote“ Erinnerung der Nachkriegsjahre auch

59 Gemälde Friedrich Schulz' in: Gartenlaube (1870), S. 753.

60 Vgl. Rüster, Chirurgie, S. 232-236. Die Wandlung setzte mit der Entdeckung der Bakterien als Verursacher der Vergiftungen ein. Eine Infektionsbehandlung mit Antibiotika kam durch die Verwendung von Penicillin erst im zweiten Weltkrieg zur Anwendung. Statistisch erlag jeder vierte Verwundete im Krieg von 1870/71 seinen Verletzungen, jedoch dürfte die Quote mindestens bei $50 \%$ gelegen haben: Sanitäts-Bericht, Bd. II, S. 95. RÜSTER, Chirurgie, S. 230. Entsprechend müssen die Verlustlisten interpretiert werden. Wenn also Bazaine in seiner Ubersicht neben den knapp $5000 \mathrm{Gefalle-}$ nen die Verwundeten der Rheinarmee aus den Kämpfen vom 14. August bis zum 7. Oktober auf ca. 23500 beziffert, ist - die Vermißten noch gar nicht gerechnet - also über kurz oder lang noch von 6000-10000 zusätzlichen Toten auszugehen. 
noch nicht durch das massenhafte sichtbare Elend grauenhaft verstümmelter Soldaten getrübt - durch Bilder, wie sie später Otto Dix gemalt hat.

Aber auch 1870/71 gab es die Verstümmelten und Versehrten, unter ihnen solche, die sich über Monate oder Jahre quälten, ehe sie an den Folgen starben. Es sollen gleich einige Beispiele folgen. Schwerverwundete, die im $\mathrm{Ku}-$ gelhagel hilflos liegengeblieben waren, erhielten im besten Fall einen notdürftigen Verband und wurden früher oder später abtransportiert. Eine brutale Selektion entschied über ihr Schicksal. Nicht selten lagen sie Stunden, manchmal sogar Tage auf dem Schlachtfeld, oft unter furchtbaren Schmerzen, bis zuletzt auf Hilfe hoffend. Besonders schlimm wurde es im Winterkrieg an der Loire, als Frost und Schnee das Leiden der Verwundeten ins unermeßliche steigerten. Nachstehende Krankenblätter stammen aus den akribisch geführten Sanitätsberichten des preußischen Kriegsministeriums. Sie verdeutlichen das Leiden in einem anamnestisch-kalten Stil:

E. F., Musketier vom 7. Westfälischen Infanterie-Regiment No. 56. Am 16. August 1870: Gewehrschuß durch die linke Lungenspitze. Eingang durch die Schultergräte. Ausgang unterhalb des Schlüsselbeines. - Schultergräte gesplittert. Nach der Verletzung brach der Verwundete zusammen und blieb lange bewußtlos liegen. Im höchsten Grade erschöpft und kaum fähig, Auskunft zu geben, wurde er erst am 18. August an einer einsamen Stelle des Schlachtfeldes gefunden und am 19. August in ein Lazareth gebracht. Die Kleidungsstücke waren stark mit Blut durchtränkt, die Wundöffnungen mit angetrockneten Blutgerinnseln verklebt. Starke Blutungen aus der Wunde. Reichlicher blutiger Auswurf. Heftigste Athemnot. Gesicht blau, häufiger Husten, Stiche in der Brust. Sprache sehr erschwert, abgebrochen. Genaue Untersuchung nicht möglich. - Trotz der Darreichung von Reizmitteln trat bereits in der nächsten Nacht der Tod $\operatorname{ein}^{61}$.

J. L., Grenadier vom 2. Garderegiment zu Fuss - 25 Jahre. Am 18. August 1870: 2 Schüsse durch die Brust, links und rechts. Links: Eingang im 6. Zwischenrippenraum, nach aussen vom Herzen; Ausgang unterhalb des linken Schulterblatts. Rechts: Eingang durch die 5. Rippe in der Warzenlinie; Ausgang unterhalb des rechten Schulterblatts. Ein dritter Schuß hat die Handwurzelknochen mehrfach zertrümmert. - Links die 5. und 6. Rippe, rechts die 5. Rippe zersplittert. Traf in nahezu hoffnungslosem $\mathrm{Zu}$ stande in dem Reservelazareth zu Gotha am 27. August ein. Blutiger Auswurf. Auf beiden Seiten in der Umgebung der Schusswunden handgrosse Verdichtung des Lungengewebes. Nicht sehr große Athemnot. Bewußtsein stark benommen, Fieber sehr bedeutend. In den nächsten Tagen etwas Besserung; grosse, fast unerträgliche Schmerzen an der Hand; Amputation des Vorderarms im unteren Drittel am 5. September. Fieber sehr heftig. 6. September: Fieber geringer, Puls 110. 10. September: Neue Verdichtung an der Lungenspitze; heftiges Fieber. 15. September: Neuer Nachschub von Lungenentzündung mit eitrig-blutigem Auswurf. Die Amputationswunde heilt schnell, ist am 20. September geschlossen. 7. Oktober: Rechts überall bronchiales Athmen, links nur in der Umgebung des Schusskanals. Die Schwäche nimmt von Tag zu Tag zu, die rechtsseitige Lungenentzündung führt den Tod herbei. Gestorben am 9. Oktober $1870^{62}$.

H., vom 3. Garde-Regiment zu Fuss, verwundet am 18. August 1870 bei Gravelotte:

61 Sanitäts-Bericht, Bd. III, Spezieller Theil I, S. 522.

62 Ibid S. 526. 
Granatschussbruch des rechten Oberschenkels im oberen Drittel. Einschnitt vorn behufs Entfernung des Granatsplitters. Anfangs Gypsverband; später doppelt geneigte Ebene. Im 3. Monat war noch keine Verwachsung des Bruches erfolgt; das Bein um 12 $\mathrm{cm}$ verkürzt und stark gekrümmt. Die Eiterung reichlich und übelriechend; anhaltende Durchfälle. Streckverband. Im 4. Monat lebhafte Schmerzen. In Chloroformbetäubung ein Knochenstück mit der Säge entfernt, wodurch eine grosse Knochenhöhle entsteht. Gypsverband. Unter zunehmenden Durchfällen, hohem Fieber, Frösteln erfolgt der Tod am 1. Januar 1871 an Pyämie (Blutvergiftung) ${ }^{63}$.

P. H., Musketier vom 5. Brandenburgischen Infanterie-Regiment No. 48. - 22 Jahre. Am 18. August 1870: Gewehrschuss. Eingang an der linken Brustseite, $5 \mathrm{~cm}$ unterhalb der linken Brustwarze. Geschoss an der rechten Brustwand, $4 \mathrm{~cm}$ unter dem Schwertfortsatz, durch Einschnitt entfernt. Eiter im Brustfellsack. Vom 26. November 1870 bis 23. Februar 1871 im Garnisonslazareth Cüstrin. März 1871: Fistel, in Verbindung mit der linken Brusthöhle, Husten, Auswurf, Abmagerung. 1872: Luft und Eiter im linken Brustfell. Trägt ein Gummirohr, um den Eiterabfluss zu erleichtern. 1874: Derselbe Zustand. An den Folgen der Brustfelleiterung gestorben (1875) 64 .

Auch für Schädel- oder Unterleibsverletzungen ließen sich Beispiele zur Genüge auflisten, wobei Bauchverwundungen die allgemein schwersten waren und fast immer zu einem schnellen Tod führten: Durchschnittlich starben in diesem Fall sieben von zehn Betroffenen ${ }^{65}$. Jedoch gab es noch Schlimmeres, etwa bei Verwundungen der Lunge: Hier kam zu den unerträglichen und ohnehin kaum zu lindernden Schmerzen eine durch aufsteigende, zum Teil hochgradige Atemnot hervorgerufene permanente Unruhe und quälende Todesangst, die die Tage oder Wochen des Sterbens zur Ewigkeit werden ließen. Man muß die oben aufgeführten kalten und fast ein wenig expressionistisch anmutenden Berichte mit den Bildern vom weichen, sanften, romantischen Tod der stets schön und unversehrt daliegenden Helden kontrastieren, wie sie in der Heimat Verbreitung fanden, um sich eine Vorstellung davon zu machen, welche Kluft zwischen der erschreckenden Kriegswirklichkeit und den verzerrten Wahrnehmungen davon im Hinterland bestand 66 . Wie so oft während der großen Kriege boten sich der Medizin, gleichwohl überfordert und dem massenhaften Leiden oft hilflos gegenüberstehend, neue, ungeahnte Möglichkeiten, am Menschen versuchsweise Hand anzulegen und anlegen zu müssen. Experimentierfelder für Chirurgie, Anatomie, Neurologie oder die in den Anfängen steckende Psychiatrie taten sich auf, und die mühselige Forschungsarbeit langer Friedensjahre wurde quasi über Nacht durch revolutionierende Entdeckungen überboten. Über den Opfern erhob sich der Fortschritt. Bleiben wir aber, bevor wir uns der Lage in den Lazaretten zuwenden, noch einen Augenblick auf dem Schlachtfeld.

Einzelne Betroffene entschieden nämlich noch bevor Hilfe kommen konnte, ihrer verzweifelten Lage durch Selbstmord ein Ende zu machen.

\author{
63 Ibid S. 471. \\ 64 Ibid S. 472. \\ 65 Ibid S. 613. \\ 66 Abb. 8, aus: Gartenlaube (1870), Nr. 49, S. 824.
}




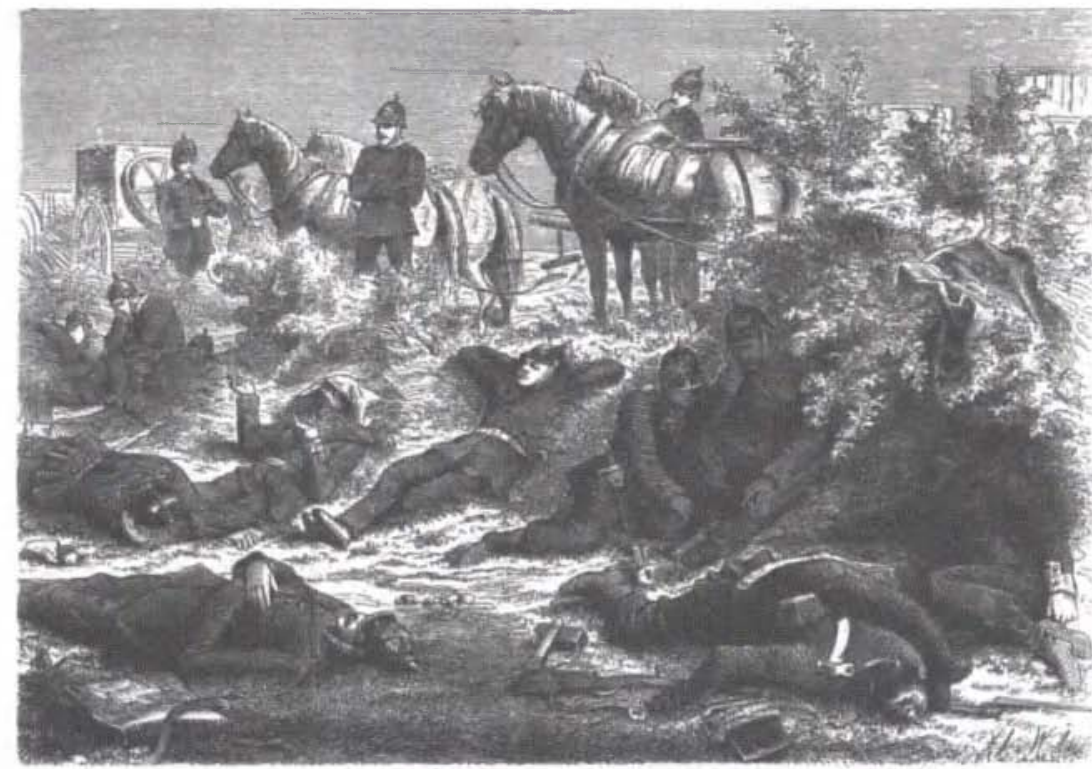

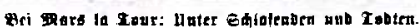

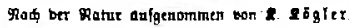

Abb. 8: Bei Mars la Tour: Unter Schlafenden und Toten. Qucllc: Gartenlaube (1870), Nr. 49.

Mancher hatte sich in Erwartung des Endes mit dem Bild seiner Frau oder seiner Kinder getröstet. Die Gartenlaube brachte das Bild eines bei Vionville gefallenen Füsiliers, der sterbend sein Notizbuch mit dem Gedicht seiner Liebsten hervorgeholt hatte ${ }^{67}$. Wenn Schwerverwundete das Glück hatten, rasch aus der Feuerzone gebracht zu werden, geschah dies durch Krankenträger und Sanitäter, welche die schwere Entscheidung zu treffen hatten, wem sofortige Hilfe zu gewähren war und wer weiter ausharren mußte: Gewehre, abgeschnallte Koppel und entfaltete Mäntel wurden zu Tragen umfunktioniert, auf die man die Verwundeten legte. Andere konnten nur vertröstet werden ${ }^{68}$. In manchen Fällen halfen couragierte Kameraden, die sich in der Nähe befanden. Im Augenblick höchster Gefahr für das eigene Leben gehörte Kaltblütigkeit und Mut dazu, einem Verwundeten zu helfen. Auch wenn es nur bei einem notdürftigen Verband, tröstenden Worten und einem Schluck Wasser blieb, so konnte dies in einigen Fällen Leben retten, zumindest aber den momentanen Überlebenswillen der Betroffenen stärken. Wo es möglich war, verwehrtẽ man dem Gegner die Hilfe nicht. Gefangenè, Ver-

67 Ibid Nr. 39, S. 633.

68 FRITSCH, Erinnerungen, S. $64 \mathrm{f}$. 
wundete und Wehrlose galten als personnes sacrées. Wenn schwere Gliedmaßenverletzungen, die häufig mit Schock und Ohnmacht verbunden waren, nicht sogleich ver- bzw. abgebunden wurden, hatten die Betroffenen keine Überlebenschance. Hier entschied die erste Hilfe über Leben und Tod, wofür der Bericht eines bei Gravelotte verwundeten Vizefeldwebels steht:

Die Kugeln und Granaten faßten uns von vorn und in der rechten Flanke. Das Pfeifen und Sausen war furchtbar. Vor und neben mir fielen die Leute wie Fliegen, theils still, theils erbärmlich schreiend. Das war das Furchtbarste. Auf einmal geht's: Sssst, schrumm! und ich drehte mich einmal um mich selbst, saß nieder mit Geschwindigkeit, und rief unwillkürlich: Wo ist mein Arm hin! Ich grapste in wahrer Angst mit der Linken daran herum. Alles in wenigen Secunden, sprang auf, den Säbel in der linken Faust, biß die Lippen zusammen, und drauf [...] Aber das Feuer war zu dick, zu dick; wir mußten ein Stück zurück, ich mit, und plumps! lag ich in einem preußischen Bataillon. Als ich von meiner schweren Ohnmacht erwachte, war mir Ärmel, Hemd usw. abgeschnitten, ein Preuße hatte mich verbunden. Ich stand auf, suchte wieder eine Weile meinen Arm, der noch neben mir baumelte [...] und dann taumelte ich unter wahnsinnigen Schmerzen durch Leichen, Verwundete und verwundete Franzosenschufte $[\ldots]^{69}$.

Das Schmerzempfinden im Moment der Verwundung konnte zum Teil noch gering sein, steigerte sich aber wenig später. Schußverletzungen wurden oft wie ein Stockhieb oder eine Last empfunden, die auf den Betroffenen gefallen war. Bei Gliederabrissen durch große Geschosse hatte man das Gefühl, als seien Arm oder Bein „in einer Grube stecken geblieben"70. Die Sanitätsdetachements waren pausenlos und unter ihrerseits beträchtlichen Verlusten im Einsatz und dabei doch hoffnungslos überfordert: „Am schrecklichsten war es wohl, was Verwundete betraf, in Gorze, eine solche erdrückende Menge von Verwundeten und so wenig Ärzte usw. kann sich niemand vorstellen

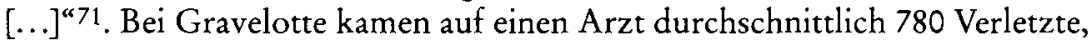
bei Sedan nur 3572! Ärzte und Pfleger, die vor allem am 16. und 18. nicht selten in die Kampfzonen geraten waren, führten einen verzweifelten Kampf um die Rettung der Verwundeten. Es fehlte an sicheren Plätzen zur Unterbringung der Schwerverletzten. Auch mußten häufig die Standorte gewechselt werden, weil die Verbandsplätze ins Feuer gegnerischer oder eigener Artillerie gerieten. So geschah es, daß am 18. August der nahe Gravelotte gelegene Pachthof Mogadar, in dem einige hundert französische Schwerverwundete untergebracht worden waren, in Brand geschossen wurde. Alle Verwun-

69 Brief von Rudolf Gehring aus St. Marie aux Chênes vom 23. August 1870, in: Rudolstädter Wochenblatt, Jg. 1870, S. 587. Der Verfasser starb wenige Tage später.

70 FISCHER, Kriegschirurgie, Bd. 1, S. 56-58.

71 P. HASE, Feldarztbriefe, S. 11. In Gorze, das unmittelbar südlich der Schlachtfelder liegt, sammelten sich zunächst alle Verwundeten und Schwerverwundeten, ehe es zum Abtransport in die rückwärtigen Lazarette wie Pont-à-Mousson kam.

72 Krocker, Krankenpflege, S. 358. Auch die Statistiken Kühlichs belegen, daß die Kämpfe um Metz an Verlusten und Verwundeten das Äußerste des gesamten Krieges darstellten. DERS., Soldaten, S. $406 \mathrm{f}$. 
deten kamen im Feuer um ${ }^{73}$. Überall herrschte Mangel an Verbands- und Operationsmaterial sowie an schmerzstillenden Mitteln. Häufig wurden auch die langen Transportzeiten den Verwundeten zum Verhängnis. Gegenüber den modernen Zügen dieses Krieges in Waffentechnik oder Infrastruktur blieb die medizinische Ausstattung noch weit zurück. Ärzte erinnerten sich später an „vorsintflutliche Zustände“:

Jedes Bataillon besaß einen zweirädrigen, außerordentlich schwerfälligen Medizinkarren mit zwei Kisten, eine für Verbandszeug, eine für Medikamente. Da nun der Bauchgurt das Pferd, das hierzulande dies anspannen an den Karren nicht kannte, belästigte, so war auch das Gefährt stets in Unordnung und kam nicht gut von der Stelle. Die Ausrüstung mit Medikamenten war etwas vorsintflutlich. So gab es einen großen Ledersack mit Brusttee! Vor Metz haben wir den Tee in der Not als Ersatz für Kaffee getrunken. Dann gab es eine Unzahl völlig unnötiger Medikamente. Was man aber täglich brauchte, z. B. Opiumtinktur, war sowenig vorhanden, daß sie an einem Tage verbraucht war ${ }^{34}$.

So fehlte es am Nötigsten, und immer wieder gingen Hilferufe nach dem Geringsten zurück in die Etappe. Neben den militärischen Sanitätseinheiten oblag es den geistlichen Orden, die Verwundeten zu pflegen und ihren Abtransport zu organisieren. Auch kam den Feldgeistlichen das traurige Amt zu, Schwerverwundete, die auf den Tod warteten, und Hinterbliebene von Gefallenen seelsorgerisch zu betreuen. Das war etwas ganz anderes, als die Waffen vor der Schlacht zu segnen. Jedoch geschah es auch, daß Priesterornat und Johanniterkreuz dazu mißbraucht wurden, Tote und Verwundete, die die Schlachtfelder bedeckten, auszuplündern. Man bezeichnete solche Personen als Feldbyänen und erschoß sie, wo man sie aufgriff, in der Regel nach kurzem Prozeß. Aus einem Kriegsgerichtsprotokoll stammt die nachstehende Aussage eines preußischen Offiziers, der am Morgen des 19. August bei Gorze auf Hilfe wartete:

[...] ich erkannte deutlich einen Mann im Feldpriesterornat und zwei Johanniter. Als die Männer bei der Gruppe ankamen, begannen dieselben mit Messer und Schere die Uniform auf der Brust jedes Einzelnen zu öffnen - wer sich etwa noch bewegte, wurde mit den Händen erwürgt, wenn sich auf der Brust nichts fand, begannen sie die Taschen und Hände zu durchsuchen, jeder Ring an der Hand eines Toten oder Verwundeten wurde mit dem Finger abgeschnitten [...], da hatte mich jedoch schon der eine bemerkt und sprang auf mich zu, ich rief aus Leibeskräften: zwei dieser Kerle liefen vorwärts, um als Wache zu stehen. Glücklicherweise fühlte ich, daß mein sechsläufiger Revolver neben mir lag, ich drückte los, der Feldpriester fiel verwundet nieder, die anderen entflohen, wurden jedoch von der herbeieilenden Feldwache noch eingeholt ${ }^{75}$.

Hier, wie auch in den noch zu behandelnden Requirierungszügen der deutschen Belagerungstruppen, lebte der alte Grundsatz vom Krieg, der sich

73 REGENSBERG, 1870/71, Bd. II, S. 261. In unmittelbarer Nähe befanden sich während des Beschusses das Große Hauptquartier und der preußische König. Ibid S. $109 \mathrm{f}$.

74 FRITSCH, Erinnerungen, S. 10.

75 Bei den Tätern handelte es sich um einen Gastwirt aus Düren (bei Bonn) und drei in Deutschland arbeitende Belgier. KÜRSCHNER, Krieg, S. 388. 
selbst ernährt, neu auf, und keineswegs fällt es selbst mit Abstand zu den Dingen leicht, eine klare Trennlinie zwischen kriegsrechtlich abgesicherten und unangemessen, ja verbrecherischen Maßnahmen zu ziehen. Faktisch wie moralisch problematisch war der vermeintlich gerechte Krieg ohnehin, weil er für längere Zeit auf fremdem Boden geführt werden mußte.

Der Weg der Verwundeten verlief gewöhnlich über die Verbandsplätze in die Feld- und von dort aus in die Heimatlazarette. Dies geschah mit Pferdewagen und anschließend per Bahntransport. Erreichte ein Verwundeter den Hauptverbandsplatz, so gab es, je nach Schwere seiner Verletzung, drei Möglichkeiten der Weiterbehandlung: War er nur leicht blessiert und noch transportfähig, wurde er in der sogenannten "gelben “ Verbandsstation grundversorgt und anschließend mit einem Diagnoseschein abkommandiert. Die weitaus meisten Fälle landeten in der "blauen“ Operationsstation. Hier fanden die ganz anderen Schlachten, nämlich die um das Leben der Verwundeten statt, und über allem dort lag ein bleierner Schleier leichenfarbig-gespenstigen Seins. Als besonders kompliziert erwiesen sich offene Trümmerfrakturen vor allem der Gelenke sowie Verletzungen der inneren Organe. In der Regel operierten die Ärzte unter Chloroformnarkose, seltener mit Äther vermischt oder unter Morphium ${ }^{76}$. Das war zweifellos eine wichtige Neuerung der Kriegschirurgie, die aber nur zum Teil wirkliche Anwendung fand, da es „bei kräftigen, den Spirituosen nicht ganz abholden Männern", wie der Experte rückblickend einräumte, bis zu 20 Minuten dauerte, ehe die Dosen wirkten ${ }^{77}$. Solange konnte aber nicht gewartet werden. Mitunter, bei kleineren Verletzungen ohnehin, verzichteten die Ärzte ganz auf die Narkose: „Man kann“, so hieß es dazu im Sinne des früher erwähnten Männlichkeitsideals von militärischer Härte, Schmerz- und Todesverachtung, „einem muthigen und frischen Soldaten schon eine gute Portion Schmerzen zumuthen, wenn man sein Ehrgefühl rege hält und seine Geduld nicht auf eine zu harte

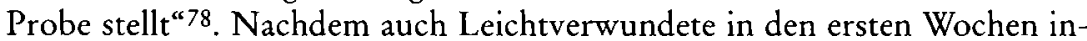
folge der Operationen wie die Fliegen weggestorben waren, ging man zu einer strenger antiseptischen Behandlung über. Anfangs noch mit bloßen Fingern und Sonden durchgeführte Untersuchungen frischer Wunden und das Entfernen von Projektilen, Kleidungsresten und Knochentrümmern unterblieben nun und wurden erst in den Operationssälen unter Desinfektion von Raum, Kleidung und Instrumenten mit Karbolsäurelösungen durchgeführt ${ }^{79}$. Auch hierin bestand ein weiterer Fortschritt, doch fehlten noch Dampfsterilisator und Gummihandschuhe sowie, wir wiederholen es, das Wissen um die Kleinstlebewesen, die Bakterien, als Verursacher der tödlichen Vergiftungen. Es ist in den Quellen immer von Miasmen und giftigen Dämpfen die Rede, denen man mit Reinlichkeit durch Desinfektion, frischer Luft

76 FISCHER, Kriegschirurgie, Bd. 2, S. 643-645.

77 Ibid.

78 Ibid S. 645.

79 Ibid S. 985. 
und von Zeit zu Zeit vorgenommenen Evakuierungen verseuchter Lazarette zu begegnen suchte. Bei schwereren Gliedmaßenverletzungen bestanden so kaum Alternativen zur Amputation, und es galt der Grundsatz, septische Kranke nicht unamputiert sterben zu lassen, wobei möglichst hoch angesetzt werden sollte 80 .

Einer dritten „roten“ Station schließlich wurden die Todeskandidaten zugeführt und dort so gut es ging gebettet und versorgt. Davon gab es um Metz im unmittelbaren Aktionsradius der Belagerungsarmee einige Dutzend. Die Sanitätszüge bildeten ebenfalls ein Novum in der europäischen Kriegsgeschichte; ihre Vorläufer waren im amerikanischen Bürgerkrieg erstmals zum Einsatz gekommen. Jedoch verband Metz und das deutsche Hinterland lediglich eine einzige, eingleisige Bahnlinie, die den Anforderungen in keiner Weise genügte. Wir sehen auch hier wieder, daß Fortschritte in der Kriegsmedizin durchaus zu verzeichnen waren, aber noch nicht zu einer effektiven Anwendung führten. Die Bahnwaggons, in denen man Verwundete und Schwerkranke dicht an dicht transportierte, waren mit Stroh ausgelegt. In infektiöser Umgebung drohten auch den Pflegern ansteckende Krankheiten:

Ich bin bis in die Nähe von Metz vorgedrungen und habe von dort einen Verwundetenzug nach Karlsruhe geleitet. Hierbei, bei dem fürchterlichen Zustand aller meiner Kranken, dem fortwährenden Verbinden ihrer zum Theil brandigen Wunden, bei dem Schlafen in Viehwägen, in denen sechs Schwerverwundete auf Stroh lagen, habe ich den Keim der Ruhr in mich aufgenommen; zugleich hat auch der Arzt an mir noch Rachendiphteritis entdeckt, die aus derselben Thätigkeit stammt ${ }^{81}$.

In Metz selbst breiteten sich Epidemien auf Grund fehlender Evakuierungsmöglichkeiten und dem Mangel an Unterkünften aus. 20000 Verwundete und Kranke überfüllten den verfügbaren Raum bei weitem. Zunächst noch in den Krankenhäusern untergebracht, mußte man bald ausweichen "dans des baraquements insalubres installés à Chambière, jusque dans des wagons amenés sur la Place Royale et à l'Esplanade [... “"82. Die Belagerer dagegen hatten mit dem zu kämpfen, was in der älteren Literatur so achtlos als das „Aufräumen des Schlachtfeldes“ bezeichnet wurde. An die 30000 Gefallene, Schwerverwundete und Sterbende lagen auf den Schlachtfeldern um Metz, als die Belagerung begann ${ }^{83}$. Es oblag den Einschließungstruppen, die Toten beider Parteien - den Franzosen war kaum Zeit geblieben, ihre Gefallenen mitzuführen - zu bestatten, was auch für solche galt, die unmittelbar nach den

80 Ibid.

81 NIETZSCHE, Werke, Bd. III, S. 69 f. Nietzsches spätere Krankheit könnte von daher rühren.

82 "Die Stadt hat 20000 Verwundete aufgenommen, untergebracht in den Krankenhäusern, in unsauberen, auf der Chambièreinsel eingerichteten Baracken, selbst in herangeschafften Güterwaggons auf dem Place Royale und der Esplanade [...] CONTAMINE, Metz, S. 367.

83 Der Deutsch-Französische Krieg, Bd. V, S, 1501. Sanitäts-Bericht, Bd. VI, S. 160. 
Schlachten schon einmal, aber in zu geringer Tiefe begraben worden waren. In einem Armeebefehl vom 22. August hieß es, daß dazu alle nicht beschäftigten Mannschaften heranzuziehen seien ${ }^{84}$. Die Truppenabteilungen erhielten einen entsprechenden Bezirk überwiesen, innerhalb dessen die Gefallenen in einem Massengrab vereint werden sollten:

Auch die zurückgebliebenen Landbewohner wurden dazu herangezogen; da aber Leichen und Pferdekadaver bei dem harten Boden vielfach nur in geringer Erdtiefe bestattet worden waren, so entwickelten sich bald entsetzliche Miasmen. Ein gräßlicher Leichengeruch lagerte über der ganzen Gegend. Man sah sich gezwungen, die Gräber teilweise zu vertiefen, ungelöschten Kalk hineinzuschütten und die Erddecke möglichst zu erhöhen ${ }^{85}$.

Wir zündeten zur Verbesserung der Luft aus den herum liegenden Trümmern, wie Tornisterkasten, Gewehrschäften, Lafettenteilen, Zwiebackskisten, und was überhaupt Brennbares aufzutreiben war, mächtige Feuer an. Ein Teil der Mannschaften mußte die Massengräber ausheben, was aber bei dem schweren Lothringer Tonboden und den mangelhaften Werkzeugen nur mit großen Schwierigkeiten zu bewerkstelligen war. Der andere Teil der Mannschaften schaffte die Toten an die Gruben herbei und zwar in der Weise, daß immer zwei Mann einen Gefallenen mit je einer Hand am unteren Hosenbein anfaßten, mit der anderen Hand hielten sie sich die Nase $\mathbf{z u}^{86}$.

Weiter fiel es den Totengräbern zu, die Identität der Gefallenen festzustellen und ihre Hinterlassenschaftsstücke in Verwahrung zu nehmen. In vielen Fällen war dies wegen der bis zur Unkenntlichkeit verstümmelten und verformten Körper kaum mehr möglich. Manchmal hatten Krankenträgerkompagnien, die unmittelbar nach den Gefechten vorgegangen waren, eine Identifizierung bereits vorgenommen. An Hand der Blechmarken, die die Soldaten auf der Brust trugen - sie wurden auch Totenmarken genannt, und mancher warf sie aus Aberglauben weg - konnten die Gefallenen registriert werden. Da auf der Brust auch der Geldbeutel getragen wurde, unterstellte man den Nachforschenden gern, sie würden nur nach dem Geld suchen, und nannte sie bissig die Universalerben ${ }^{87}$. Auch andere Wortschöpfungen wie Feldbyänen oder Nasenquetscher - so bezeichnete man die flachen Särge für im Lazarett verstorbene Soldaten ${ }^{88}$ - gehörten zu einer ganz eigenen, dem Landserjargon entwachsenen Begriffswelt, in der die traurigen Phänomene des Kriegsalltags mit Zynismus und schwarzem Humor verarbeitet und gleichsam rhetorisch-bildhaft dokumentiert wurden. Freilich konnten Diebstähle bei derlei Begräbnisdienst nie ausgeschlossen werden, zumal im Gegensatz zu Patrouillengängen hier auf Freiwillige kaum zu rechnen war. Zeitweise hatte man auch erwogen, die modernden Leichname zu verbrennen, doch fehlte es an Gespannen, um sie zusammenzufahren. Die Totengräberarbeit blieb für viele Soldaten das Horrorszenario des ge-

84 GolTz, Feldzug, S. 179.

85 RegENSBERG, 1870-71, Bd. II, S. 272.

${ }^{86}$ HAAS, Kriegs-Erinnerungen, S. 9.

87 FRITSCH, Erinnerungen, S. $91 \mathrm{f}$.

88 Ibid S. 150. 
samten Krieges. Mancher wurde krank darüber oder konnte vor Ekel keine Nahrung mehr aufnehmen ${ }^{89}$. Ins Gedächtnis der Betroffenen serkten sich jene schaurigen Erlebnisse so tief ein, daß sie zeitlebens davon nicht mehr los kamen:

Man vergaß die Schlachten, das Schießen, das Biwakieren im Freien bei eisiger Kälte, „aber das Totengräbergeschäft bei St. Privat“, so ein EinjährigFreiwilliger, „verfolgt mich immer noch im Traum, das war zu schrecklich“90.

$\mathrm{Zu}$ allem Unglück verlangten Angehörige gefallener Offiziere noch, deren Leichen ausfindig zu machen und nach Deutschland zu überführen. Diesen wahnwitzigen Wünschen versuchte man zunächst nachzukommen, unterließ es erst, als ein Teil der dabei eingesetzten Leute an Infektionen gestorben war:

Frau von Röder hat den König um die Leiche ihres gefallenen Mannes gebeten; und wir haben den Auftrag auszuführen [...]. Vor einiger Zeit wurden 16 Pioniere verwandt, Leichen von gefallenen Offizieren auszugraben. Die Leichen sind nur zwei bis drei Fuß vergraben, also in Folge des Regens fast verwest. Sämtliche Pioniere haben den Typhus von der Arbeit bekommen, einige starben [...]. Bedenke übrigens, daß in einem Grab oft mehrere liegen, daß man die Züge nicht mehr erkennen kann und eine Nachsuche übelster Art halten muß91.

Über den gesamten Zeitraum der Belagerung hinweg erfüllte Verwesungsgestank die Stadt und die umliegenden Stellungen. Schwerverwundete, deren Tod erwartet wurde, waren zudem in Gehöften und Dörfern sowie den erwähnten „roten“ Sterbestationen um Metz liegengeblieben. Meist bestattete man sie gleich an Ort und Stelle. Der sich später in Friedenszeiten an jenen Orten ausbreitende „zivile Grabkult“ mit seinen Obelisken, Kreuzen oder Findlingen ${ }^{92}$ ließ nicht mehr im geringsten ahnen, was da zuvor geschehen war.

Infolge der blutigen Schlachten und zusätzlich begünstigt durch den langen Aufenthalt der Truppen wurde Metz noch während, vor allem aber dann nach dem Krieg zu einer einzigartigen Totenstadt. Zunächst bedrängen die Toten noch die Lebenden, später mobilisieren und erheitern sie. Überall im Umkreis entstanden Gräberfelder, Denkmäler und Alleen, an deren Verschönerung man fortwährend arbeitete. Fast jeder einzelne Truppenteil hatte seinen Platz oder bekam ihn im Laufe der Zeit. Wo zunächst eine schlichte Grabkultur mit Holzkreuzen und Kränzen gepflegt wurde und „der Pietät von der Hand Genüge getan“ war ${ }^{93}$, erhob sich nach Kriegsende ein politischer Totenkult, der die Gefallenen zu nationalen Heroen stilisierte. Steinerne Monumente ersetzten die ursprünglich einfache-

89 DelbrücK, Kriegskunst, S. 392.

90 RegensBerg, 1870-71, Bd. 2, S. 272.

91 KRETSCHMAN, Kriegsbriefe, S. 127.

92 MAAS, Politische Ikonographie, S. 201.

93 KRETSCHMAN, Kriegsbriefe, S. 118 u. 127. 
ren Formen und standen zugleich für den Übergang von einer historischkonkreten zur mythischen Erinnerung. Alljährlich fanden nun Gedenkfeiern statt, und die Stadtführer empfahlen Wanderungen über die Schlachtfel$\operatorname{der}^{94}$. Der zum Grenzraum gewordene Platz geriet zur Pilgerstatt für Schlachtenbummler und Nationalisten, zum Instrument einer gezielt um Identitätsbildung bemühten Kulturpolitik. Von deutscher Seite wurde vor allem dem das Schlachtfeld von Gravelotte überragenden Gedenk- und Aussichtsturm eine symbolische Funktion des Wachens im Grenzbezirk zugeschrieben. Zugleich klang dieser monumentalische Appell in Richtung einer nationalen Einheit, die es auf Dauer zu sichern galt ${ }^{95}$. Doch blieb dies, im Vergleich zu den im nationalen Maßstab institutionalisierten Sedan- und Reichsgründungsfeiern, eher auf die lokale und regionale Ebene beschränkt. Auch für die einheimischen Franzosen kompensierten die Gedenkfeiern vor Ort die fehlende offizielle Erinnerung an die Niederlage ${ }^{96}$. Ihre Denkmäler atmeten, wie das bei Mars-la-Tour in Gestalt einer trauernden, aber eben der Grenze und den provinces perdues zugewandten Mutterfigur, den Geist der Revanche ${ }^{97}$. Im Gegensatz zur deutschen Seite bestimmten patriotische, entlang der neuen Grenze postierte Frauengestalten, wie Jeanne d'Arc, $\mathrm{Ma}$ rianne oder die in typischer Tracht erscheinende Lothringerin die französische Denkmalskonzeption ${ }^{98}$. Schon während der revolutionären Unruhen der Belagerungszeit hatten Frauen eine gewisse Rolle gespielt und waren zum Anlaß kultureller Konstruktionen geworden, worauf später noch näher eingegangen werden soll. Ein mehr und mehr auf Verdrängung der Schrecknisse zulaufendes Siegesbewußtsein hier und die Trauerarbeit um die année terrible dort dominierten fortan die Intentionen der Erinnerungskultur. In Frankreich gedachte man verständlicherweise lieber der Schlachten von Bouvines oder Valmy, wo bekanntlich die Deutschen verloren hatten ${ }^{99}$. Jene wiederum legten im spannungsreichen Grenzraum zwar Wert auf maßvolle und dem Gegner Ehre gebietende Formen der Erinnerung ${ }^{100}$, jedoch überwog im Inland das heldisch motivierte, jede kritische Auseinandersetzung mit den Kämpfen vom August 1870 überdeckende Andenken.

94 Metz und die Schlachtfelder, S. 24 f. Ein Überblick über „Denkmäler und Kriegergräber" der Deutschen Buchhandlung ,Georg Lang in Metz von 1876 wurde auch mit einer englischen Übersetzung versehen. Neuere Übersicht mit Abbildungen der Denkmäler auf den Schlachtfeldern: RoHdE, Geiger, Militärgeschichtlicher Reiseführer Metz.

${ }_{95}$ Durch nationale Spenden finanziert wird er 1895 zum 25. Jahrestag der Schlacht eingeweiht. MAAS, Politische Ikonographie, S. 201

96 VOGEL, Nationen im Gleichschritt, S. 194.

97 MaAS, Politische Ikonographie, S. 211-215 (mit Fotos).

98 Ibid.

99 Duby, Sonntag, S. $184 \mathrm{f}$.

100 Ganz anders 1906, als das Denkmal für die Gefallenen der Schlacht bei Jena in Vierzehnheiligen anläßlich der Hundertjahr-Gedenkfeier eingeweiht wurde. Die Kreuz-Inschrift nach Theodor Körner: „Vergiß die treuen Todten nicht", galt nur den deutschen, nicht mehr den französischen Gefallenen. Vgl. STEIGER, Schlacht, S. 63. 
„Das eben“, so hieß es in einem der vielen an die Metzer Schlachten erinnernden Vorträge späterer Zeit,

ist das bestimmende Merkmal einer großen Zeit, daß die sie tragende Generation, hinweg sehend über die engen Grenzen der eigenen Existenz, sich müht und sich opfert für das Wohl der kommenden Geschlechter, und so konnte auch die deutsche Einheit nur empor wachsen wie die Eiche am Heldengrab ${ }^{101}$.

Im geschichtsteleologisch und fortschrittsoptimistisch aufgeladenen Tonfall erfährt das Soldatensterben vor Metz seine nationale Weihe, wird so zum Symbol einer neuen Staatsordnung, zu einem Altar des blutig geeinten deutschen Vaterlandes. Und schließlich ist es bezeichnend, daß noch bei den Reichsgründungsfeiern der Weimarer Zeit - jetzt Kundgebungen vor allem gegen den Vertrag von Versailles und das neue republikanische Staatswesen den „Veteranen von 1870" in den Sälen die vorderen Plätze reserviert blieben ${ }^{102}$.

101 Helmuth, Die Preußischen Garden, S. 82. Dazu auch StÄhlin, Krieg 1870/71, S. 70. Vgl. auch HARDTWIG, Patriotismus, S. 185-187.

102 Universitäts-Archiv-Jena, Bestand BA, Nr. 1828. Mappe „Reichsgründungsfeiern“. 